\title{
Nondestructive Testing and Evaluation Methods for Rail Welds in Japan
}

\author{
Hideki SHITARA \\ Senior Researcher,
}

\author{
Yoshihiro TERASHITA \\ Researcher,
}

Yasuto FUKADA

Senior Researcher, Laboratory head, Rail welding, Track Technology Div.

\author{
Mitsumasa TATSUMI \\ Assistant Senior Researcher,
}

\begin{abstract}
In Japan, four types of welding methods, that is, flash welding, gas pressure welding, enclosed arc welding and thermite welding are applied to rail welding. All welds are inspected by nondestructive inspection right after welding in order to assure the reliability of rail welds. However, rail weld failures, which are initiated from weld discontinuities, rarely occur. It is thought that welds performed by fusion welding such as enclosed arc and thermite welding have less reliability than those by flash and gas pressure welding, because some weld discontinuities are easily generated. In this paper, the features of rail weld failures and the inspection methods for rail welds in Japan are introduced. Moreover, the improvements of the ultrasonic inspection method for preventing rail weld failures are discussed. Consequently, the double-probe technique of ultrasonic inspection method is suitable to detect discontinuities in rail welds. The relationship between weld quality and property, such as rupture load and fatigue strength, is clarified by applying this method to rail fusion welds. Rail weld failures have gradually decreased since the adoption of this inspection method to fusion welds.
\end{abstract}

Keywords : rail welding, fusion welding, weld discontinuity, nondestructive test, ultrasonic inspection, double-probe technique, bending fatigue strength

\section{Introduction}

In Japan, four types of welding methods, that is, flash welding (FW), gas pressure welding (GP), enclosed arc welding (EW) and thermite welding (TW) are applied to rail welding. It is well known that welded portions are generally the weakest portion in constructions. Welds in continuous welded rails are also no exception. Rails are one of the most important parts for the safety and transportation in railways. Therefore, the high reliability has to be assured for rail welds.

In Japan, all welds are inspected by nondestructive inspection right after welding in order to assure the reliability of rail welds. However, rail weld failures rarely occur. Most of rail weld failures are initiated from the weld discontinuities. It is said in Japan that welds by fusion welding have less reliability than those by FW and GP, because fusion welds tend to easily cause some weld discontinuities.

In this paper, we introduce the features of fusion weld failures and the inspection methods for rail welds in Japan, and discuss the improvements of the manual ultrasonic inspection method which is applied to prevent failures of rail weld performed by EW and TW.

\section{Typical morphology of rail weld failures}

Figure 1 shows the transition of the number of welding from 1984 to 2001 . Figure 2 shows the transition of the number of rail weld failures from 1985 to 2001 . The number of rail weld failures of TW and EW are larger

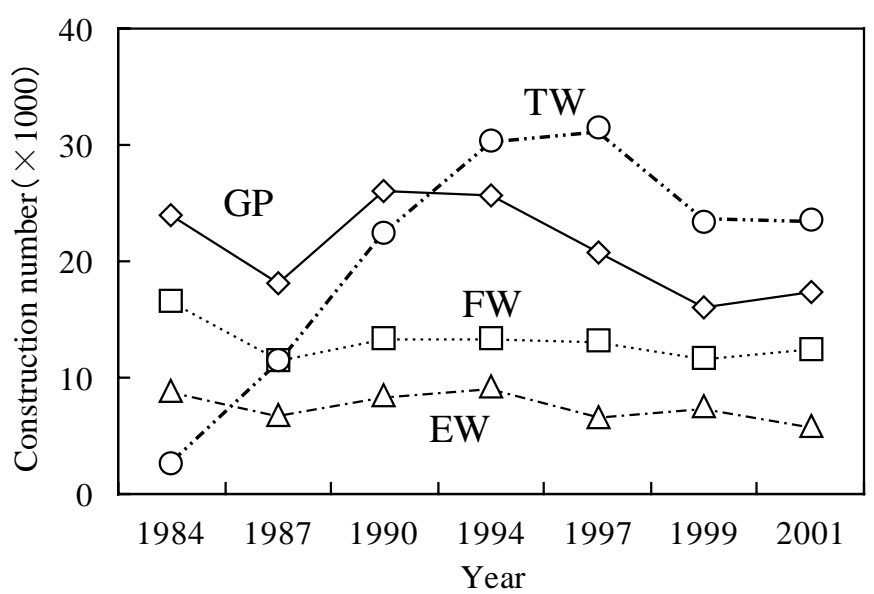

Fig. 1 Transition of the number of welding applications from 1984 to 2001

than that of FW and GP. Therefore, the morphology of rail weld failures in TW and EW was analyzed ${ }^{1) 2}$.

Typical fracture surfaces are shown in Fig. 3 to 6 . Figure 3 shows the lack of fusion caused by incomplete preheating or welding out of standard root gap, and Fig. 4 shows a solidification crack caused by the rail movement during welding in TW welds. All these defects account for about $70 \%$ of the failures of TW welds and occur in the rail base area ${ }^{3}$. Figure 5 shows a liquation crack in heat-affected zone, and Fig. 6 shows the lack of fusion in EW welds. As for the EW welds, the ratio of the transverse failure from the weld discontinuity in the head area is rather higher than that of the transverse failure from 


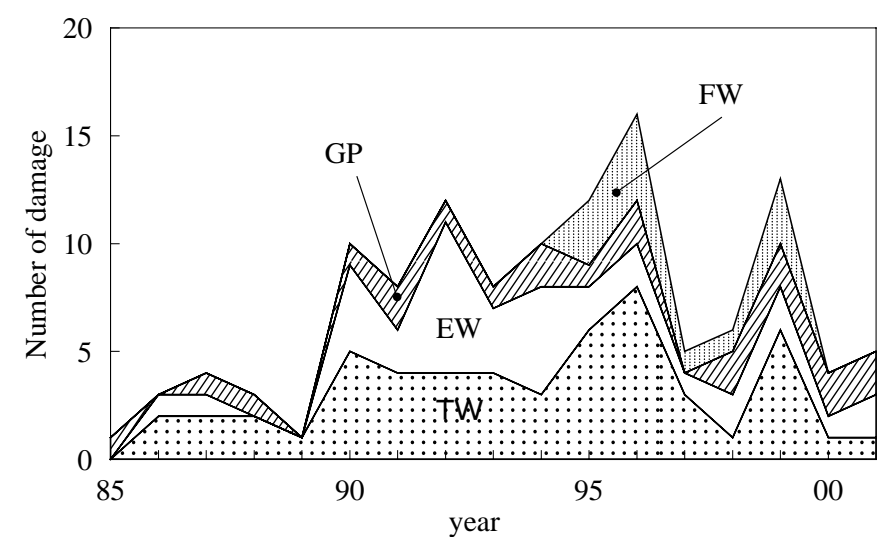

Fig. 2 Transition of the number of rail failures from 1985 to 2001

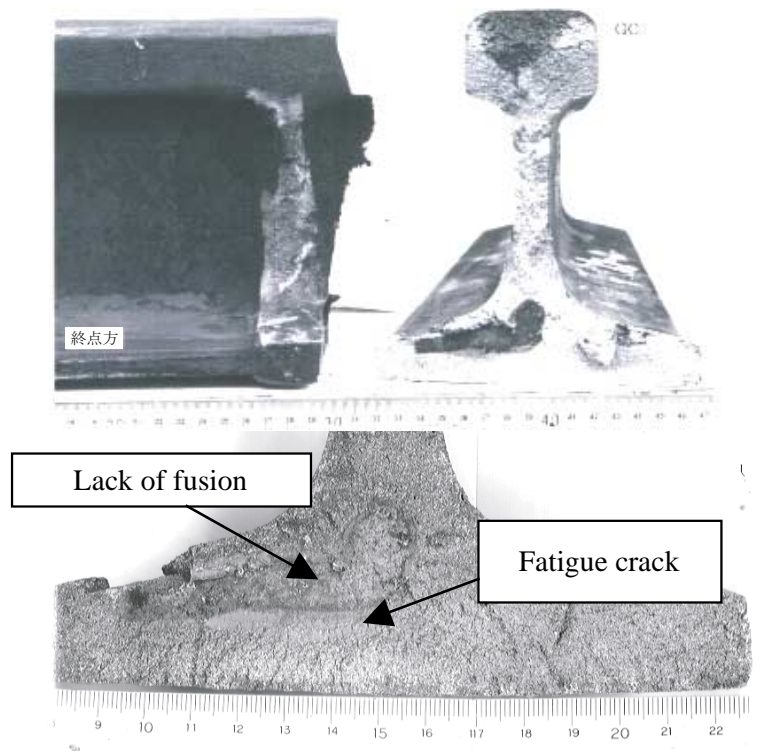

Fig. 3 Lack of fusion in TW weld

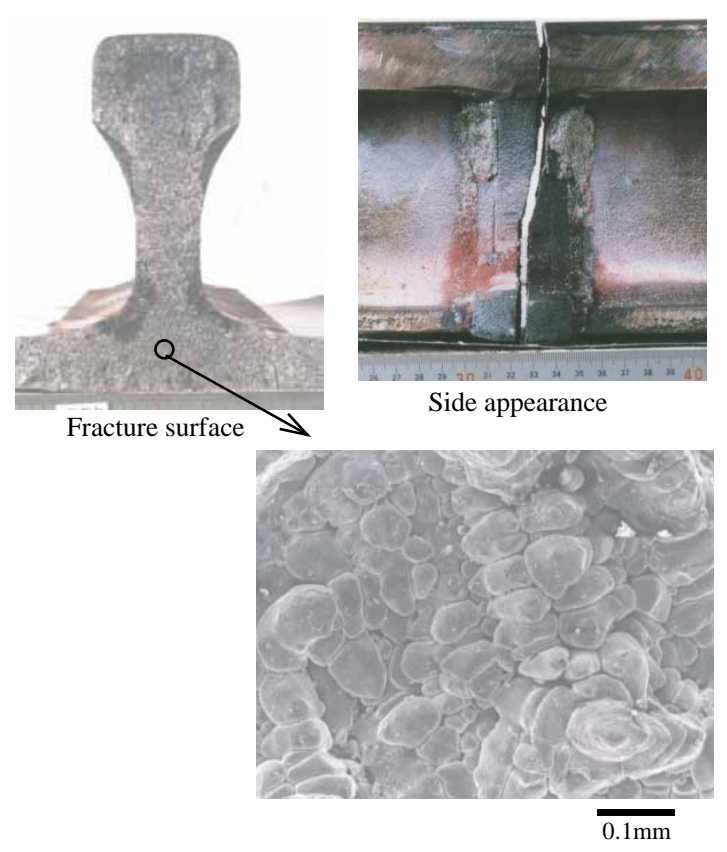

Fig. 4 Solidification crack in TW weld

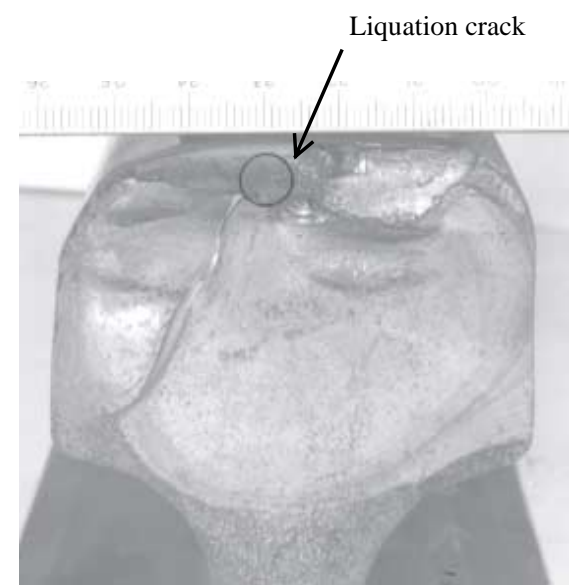

Fig. 5 Liquation crack in EW weld

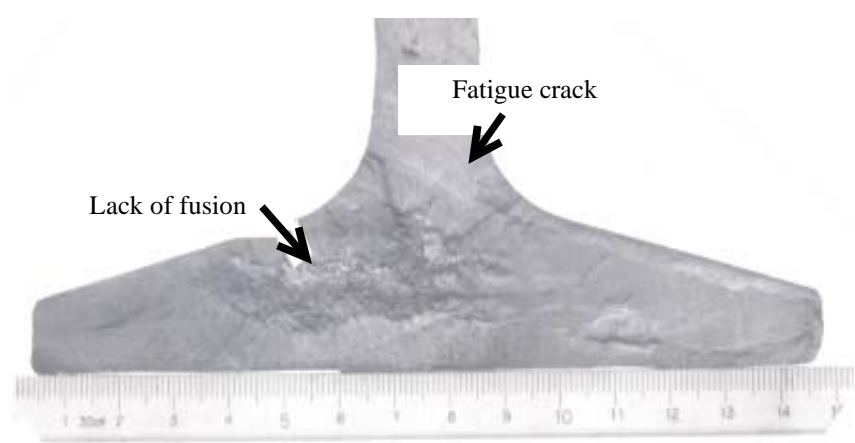

Fig. 6 Lack of fusion in EW weld

the weld discontinuity in the base area ${ }^{3)}$. From this result of analysis, it is understood that most damage forms in the fusion welds are a transverse failure from the weld discontinuity of the base area.

After installation of rail welds into tracks, large discontinuities and/or propagated cracks in the rail head and web are easily found by inspection using a rail flaw detection car. However, it is difficult to find those in the rail base area except in the area right under the rail web. Therefore, application of the manual ultrasonic method to the inspection right after welding, which can easily inspect the rail base area, is important for preventing the transverse failures initiated from discontinuities in the rail base.

\section{Nondestructive inspection for welds}

\subsection{General}

Nondestructive inspection for each rail welding, which is prescribed in the "Construction Code of Continuous Welded Rail " of JR group shown in Table 1, is performed right after welding. Failures or injuries of rails rarely occur in welded portions. They often originate from inner discontinuities of welds. Therefore, the detection of discontinuity in the weld is attached with high-degree of importance in Japan.

By the ultrasonic inspection method according to JIS $\mathrm{Z} 3060^{4)}$, discontinuities in weld are classified and evaluated. The acceptance level for weld discontinuities var- 
Table 1 Inspection for rail welds in Japan

\begin{tabular}{|l|c|c|}
\hline Inspection method & $\begin{array}{c}\text { FW } \\
\text { GP }\end{array}$ & $\begin{array}{c}\text { EW } \\
\text { TW }\end{array}$ \\
\hline Appearance inspection & O & $\mathrm{O}$ \\
\hline Magnetic particle inspection & $\mathrm{O}$ & \\
\hline Penetrant inspection & & $\mathrm{O}$ \\
\hline Ultrasonic inspection & $\#$ & $\mathrm{O}$ \\
\hline \multicolumn{2}{|c|}{$\#$ : If necessary } \\
\hline
\end{tabular}

ies in different rail parts. Generally, the acceptance level in the head and base is severer than that in the web. Magnetic particle inspection is performed for all surfaces of welds after grinding and penetrant inspection is performed for all surfaces of welds after grinding except for welds by TW. Welded portions are rejected in case cracks or defects are observed by magnetic particle inspection or penetrant inspection. Repair welding is not allowed in Japan for surface defects of rail weld.

\subsection{Ultrasonic inspection for fusion welds}

\subsubsection{Sensitivity and classification}

Ultrasonic inspection is performed by the angle beam technique using 45 degree angle probes with a nominal transducer of $10 \times 10 \mathrm{~mm}$ in dimension and a frequency

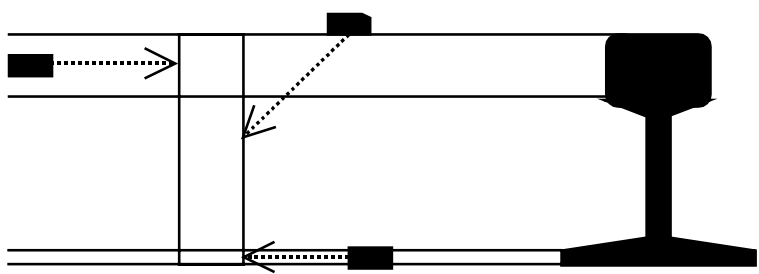

(a) Single-probe technique

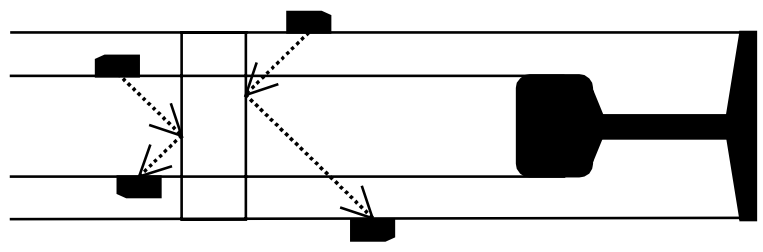

(b) Double-probe technique

Fig. 7 Ultrasonic inspection method for rail welds

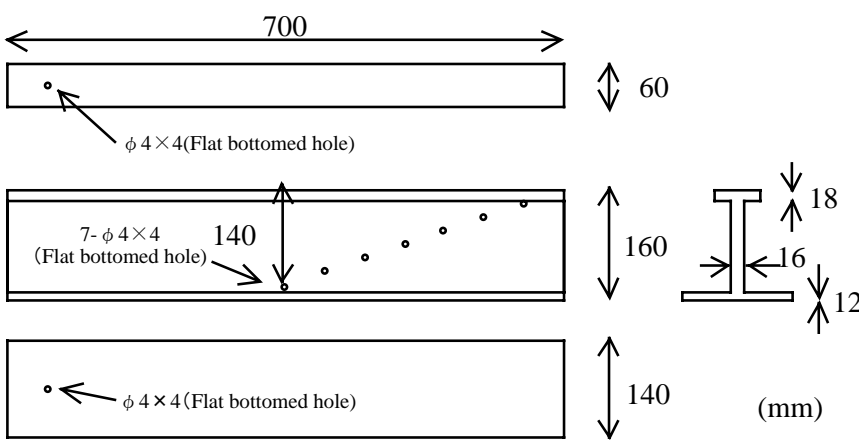

Fig. 8 Reference block for sensitivity adjustment

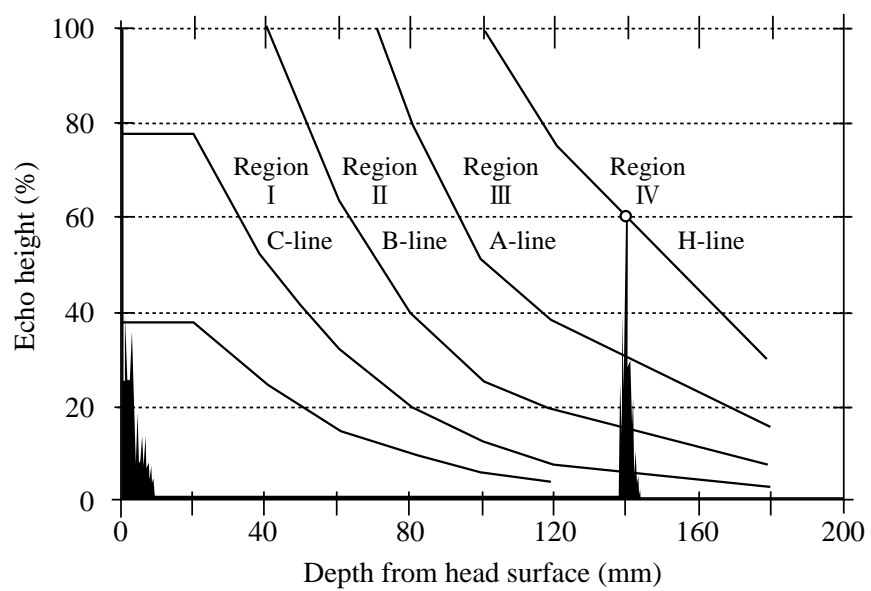

Fig. 9 Example of classification line for single-probe technique

of $2 \mathrm{MHz}$, as shown in Fig. 7. Weld flaws are classified into classes 1 to 4 according to the maximum echo height.

A reference block made of JIS $60 \mathrm{~kg}$ rail shown in Fig. 8 is used for sensitivity adjustment. This block has nine standard flat-bottomed holes of $\phi 4 \times 4 \mathrm{~mm}$. Seven standard horizontal holes in the rail web are used for adjusting sensitivity and drawing a distance-amplitude characteristic curve for the single-probe technique as shown in Fig. 7 (a). The standard sensitivity of single-probe technique, which is called the " $\mathrm{H}$ standard sensitivity," is adjusted by setting an echo height from the standard hole (which is located at $140 \mathrm{~mm}$ depth from head surface) to $60 \%$, as shown in Fig. 9. Moreover, the classification line (H-line) is made by drawing a straight line among the apexes of the echo height from the standard holes of the different depths at the "H standard sensitivity." Other classification lines are also made at the modified sensitivities from "H standard sensitivity." In other words, A-, Band C-lines in Fig. 9 are made at the sensitivity of 1/2, 1 / 4 and $1 / 8$ of the " $H$ standard sensitivity", respectively.

Two standard vertical holes in the rail head and base are used for sensitivity adjustment in the double-probe technique as shown in Fig. 7 (b). The standard sensitivities of double-probe technique are adjusted by setting an echo height from the standard holes on the head and base of reference block to $80 \%$. The head sensitivity is called the "H2 standard sensitivity" and the base sensitivity is the "B2 standard sensitivity."

The classification of echo height is shown in Table 2 . In the single-probe technique, each region in Table 2 corresponds to regions in Fig. 9. The defect evaluated by the single-probe technique is classified by both the maximum echo height and the region in which the maximum echo is detected, and the defect evaluated by the doubleprobe technique is classified by the maximum echo height alone. The recommended rejection level of the flaws in the EW weld in RTRI is shown in Table $3^{2}$. In the EW weld, this rejection level in the head area within the depth $15 \mathrm{~mm}$ from the running surface is severer than the other area, because the damage occurrence tendency ${ }^{2)}$ from the head area was taken into consideration. 
Table 2 Classification of echo height (a) Single-probe technique

\begin{tabular}{|c|c|}
\hline Region of max. echo height & Class \\
\hline Region I & 1 \\
\hline Region II & 2 \\
\hline Region III & 3 \\
\hline Region IV & 4 \\
\hline
\end{tabular}

(b) Double probe technique

\begin{tabular}{|c|c|}
\hline Max. echo height & Class \\
\hline $11 \sim 20 \%$ & 1 \\
\hline $21 \sim 40 \%$ & 2 \\
\hline $41 \sim 80 \%$ & 3 \\
\hline $81 \% \sim 11$ & 4 \\
\hline
\end{tabular}

Table 3 Recommended rejection level of EW weld on ultrasonic inspection

\begin{tabular}{|c|c|c|}
\hline $\begin{array}{c}\text { Region of estimated } \\
\text { zone in which flaws exist }\end{array}$ & $\begin{array}{c}\text { Inspection } \\
\text { Method }\end{array}$ & Rejection level \\
\hline Region I & Double-probe & Class 2, 3,4 \\
\cline { 1 - 1 } Region II & Single-probe & \multirow{2}{*}{ Class 3,4 } \\
\hline Region III & Double-probe & \\
\hline Region IV & &
\end{tabular}

\subsubsection{Feature of double-probe technique}

Fusion welds of rail have been basically inspected according to the "Nondestructive Inspection Procedure of Continuous Welded Rail" established in 1977 by the direct scan technique for which the single-probe technique was used. Though the double-probe technique is prescribed in this procedure, it hasn't been applied to fusion weld until recent years.

As mentioned above, harmful discontinuities in TW and EW welds are plane defects paralleled to the groove such as a lack of fusion and a solidification crack. Since it is hard to find these discontinuities by using the singleprobe technique, application of the double-probe technique has become important. As shown in Fig. 10, the doubleprobe technique can detect the plane defects parallel to the groove. Moreover, the maximum echo height obtained

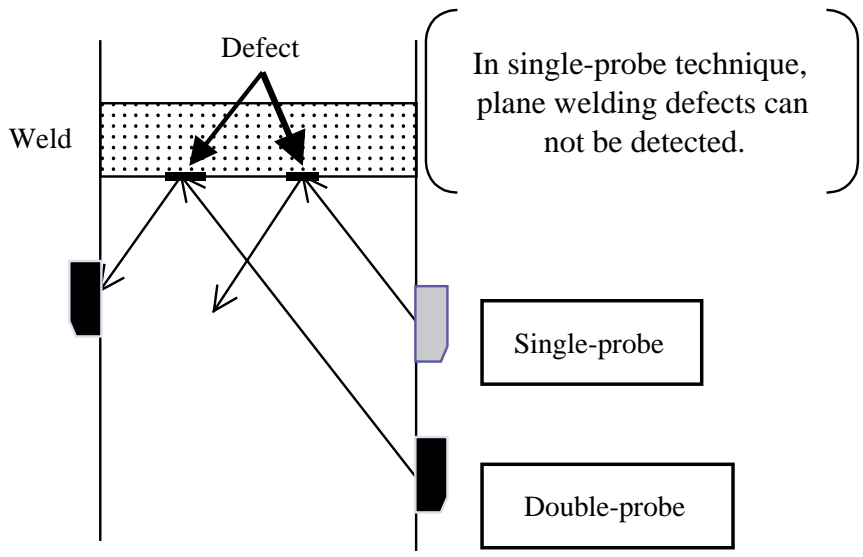

Fig. 10 Characteristic of double-probe technique

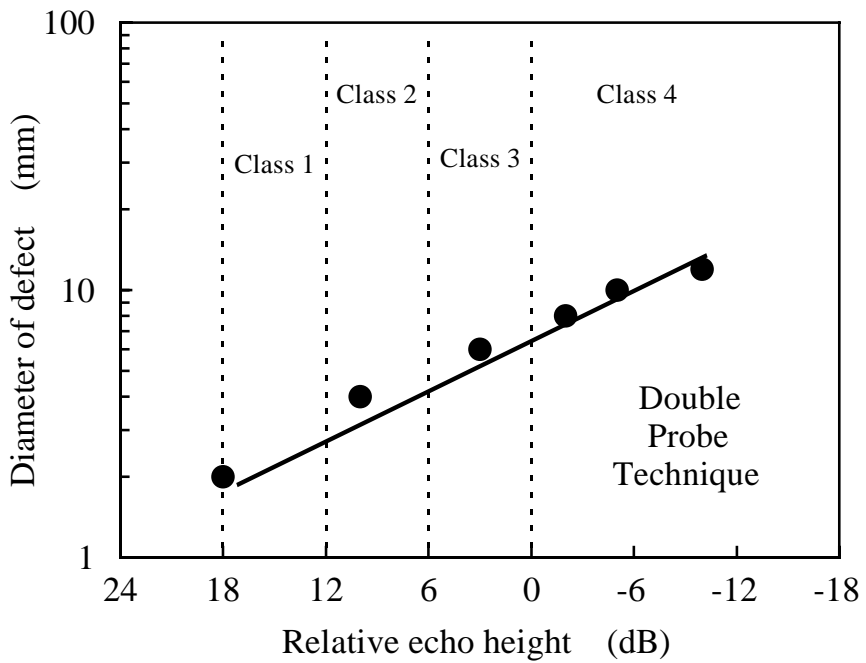

Fig. 11 Relationship between the echo height obtained by the double-probe technique and the size of defect

by the double-probe technique closely corresponds to the size of weld discontinuity as shown in Fig. 11. Furthermore, the relationship between "the result of inspection by the double-probe technique of the base area" and "the bending property of the weld" was found as shown in the next chapter. It was well understood by each JR company that the double-probe technique of the base area was effective in preventing rail weld failures. Therefore, the double-probe technique of the base area is now applicable to fusion weld of rail.

After introducing the double-probe technique as an inspection method right after welding since 1997 in most of JR, failures of rail welds by fusion welding have gradually decreased as shown in Fig. 2. In particular, this technique has a good effect on welds by TW. Recent rail weld failures in TW are almost early stage damages initiated by solidification cracks, and no rail weld failures have occurred by a lack of fusion since the introduction of this technique.

\section{Effect of classification on joint property}

This section shows the relationship between the results of ultrasonic inspection and properties in the rail base that is an important and hard portion for inspection at installation sites, as mentioned above.

\subsection{Static bending test}

Figure 12 and 13 show the relationships between the fracture load by a static bending test and the maximum echo height obtained by the double-probe technique in the rail base area of TW and EW welds, respectively. Some specimens were produced with wrong welding conditions, which were intentionally changed to create weld discontinuities.

It is clear that the fracture load with a static bending test decreases in proportion to the logarithm of maximum echo height obtained by the double-probe technique in the 


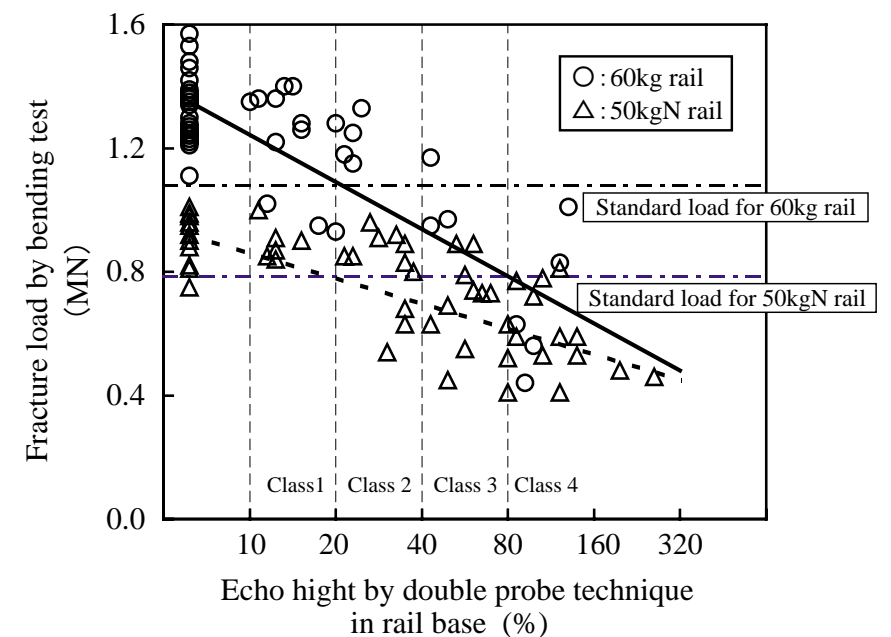

Fig. 12 Relationship between the bending fracture load and maximum echo height by the double-probe technique in rail base area of TW welds

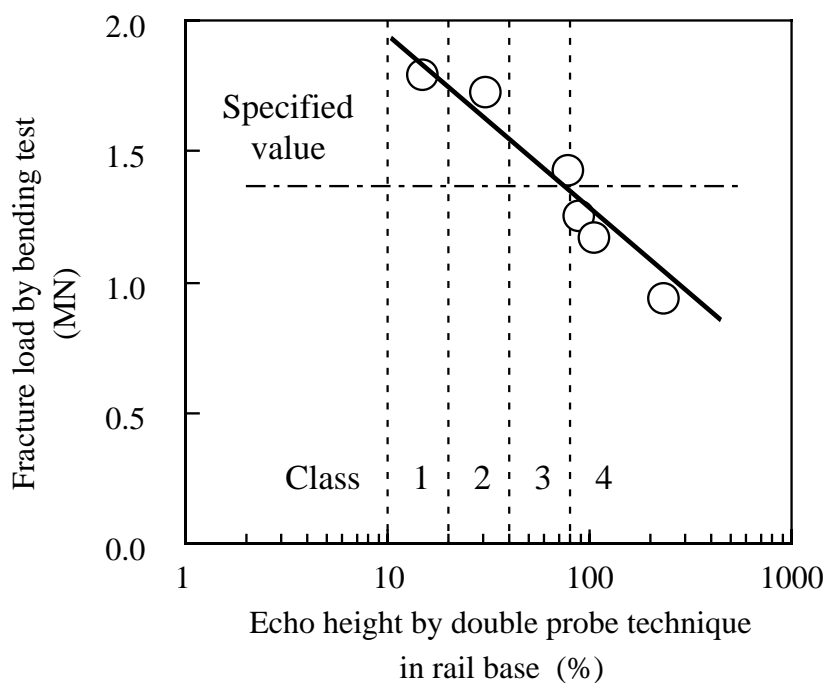

Fig. 13 Relationship between the bending fracture load and maximum echo height by the double-probe technique in rail base area of EW welds

rail base. Accordingly, the static bending strength of weld can be evaluated by the double-probe technique in the rail base.

\subsection{Bending fatigue test}

Figure 14 and 15 show the relationships between three-point bending fatigue strength and maximum echo height obtained by the double-probe technique in the rail base area of TW and EW welds, respectively. Some specimens were produced with wrong welding conditions, which were intentionally changed to create weld discontinuities. The indications of open circles $(\bigcirc)$ mean specimens of run-outs at $2 \times 10^{6}$ cycles in the prescribed stress range, and the indications of cross marks $(X)$ mean specimens failed at less than $2 \times 10^{6}$ cycles. Then it is assumed that the boundary between open circles and cross marks corresponds to the fatigue strength at $2 \times 10^{6}$ cycles.

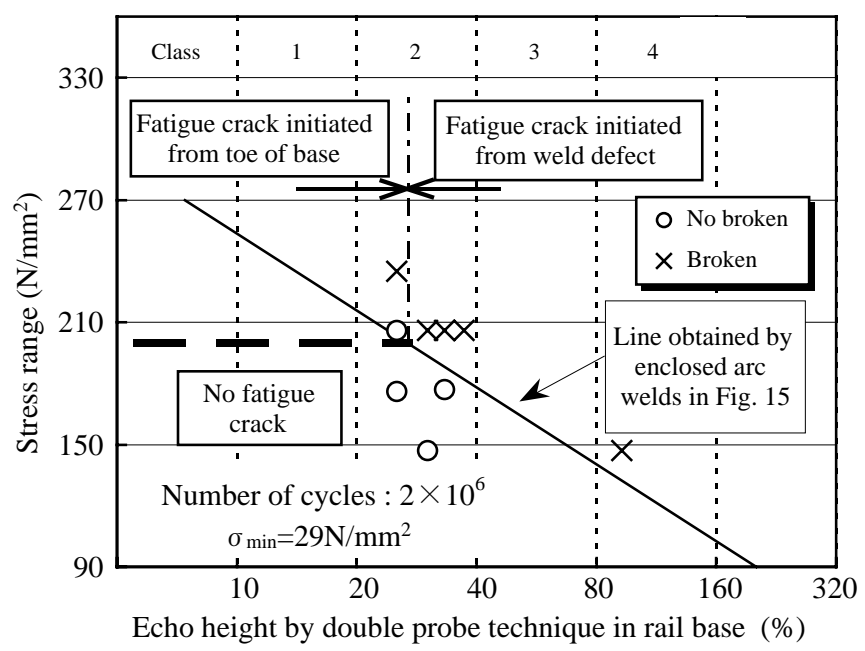

Fig. 14 Relationship between the bending fatigue strength and maximum echo height by the double-probe technique in rail base area of TW welds

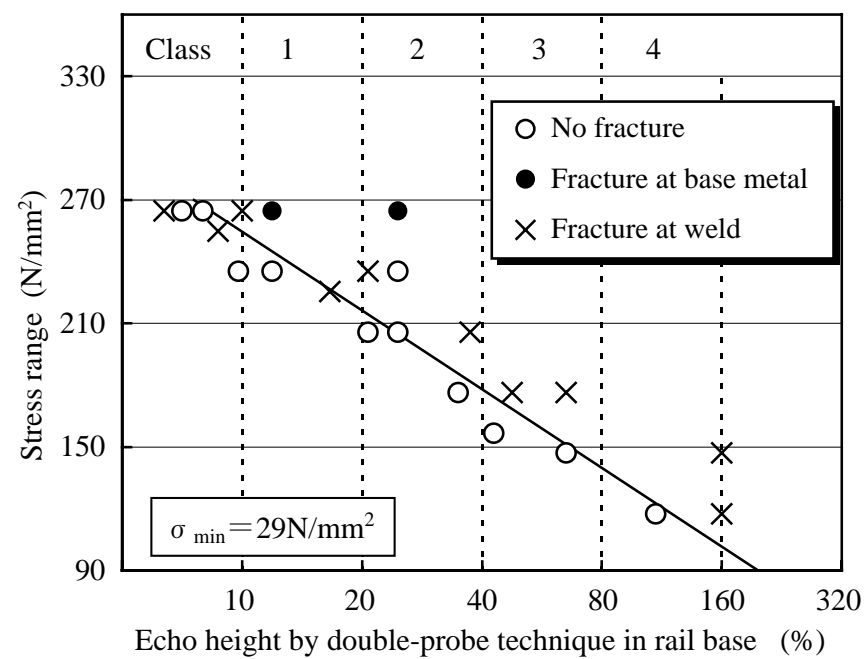

Fig. 15 Relationship between the bending fatigue strength and maximum echo height by the double-probe technique in rail base area of EW welds

The fatigue strength in the bending fatigue test decreases in proportion to the logarithm of maximum echo height obtained by the double-probe technique in rail base. Accordingly, the fatigue strength of weld can be evaluated by the double prove technique in the rail base.

In Fig. 14, the fatigue strength of sound weld by TW is estimated at about $210 \mathrm{~N} / \mathrm{mm}^{2}$ to be managed by the shape of reinforcement at weld toe. However, fatigue strength of welds by TW included a larger discontinuity, the same as that by EW.

\section{Conclusions}

Results obtained in this investigation are as follows:

(1) The majority of failures of fusion welds are transverse failures initiated from the weld discontinuities in the rail base area.

(2) The double-probe technique is effective to detect harmful discontinuities in fusion welds such as a lack of 
fusion and a solidification crack.

(3) After introducing the double-probe technique as an inspection method right after welding, the number of rail weld failures by fusion welding has gradually decreased.

(4) The static bending strength and the fatigue strength of fusion welds can be evaluated by the double-probe technique in the rail base.

\section{References}

1) Tatsumi, M. , Ueyama, K. , Yamamoto, R. and Kudoh,
S. : "Ultrasonic Inspection for Serious Defects on Fusion Welds of Rail (in Japanese)," RTRI Report, Vol.9, No.12, pp.43-48, 1995.

2) Tatsumi, M. , Shitara, H. , Fukada, Y. , Sakashita, T., Yamamoto R. and Ueyama K. : "Criteria of Soundness Evaluation on Enclosed Arc Welds of Rails (in Japanese)," RTRI Report, Vol.14, No.4, pp.37-42, 2000.

3) Terashita, Y. , Tatsumi, M. : "Analysis of Damaged Rail Weld," QR of RTRI, Vol.44, No.2, 2003. (in preparation)

4) Japanese Industrial Standard : "Method for Ultrasonic Examination for Welds of Ferritic Steel," JIS Z3060-1994 